\title{
ENTRAVES AO DESLOCAMENTO PEDONAL EM UMA CIDADE DE PEQUENO PORTE: OS NÍVEIS DE CAMINHABILIDADE NA CIDADE DE GOIÁS-GO
}

\section{BARRIERS FOR PEDESTRIAN MOVEMENT IN A SMALL TOWN: THE WALKABILITY LEVELS IN GOIAS CITY}

\section{Pedro Henrique Gonçalves, M.Sc (UFG); Thalita Pereira da Fonseca, M.Sc (UFG); Carina Folena Cardoso, M.Sc (UFG)}

\author{
Palavras Chave \\ Caminhabilidade; Qualidade Espacial Urbana; Cidade de Pequeno Porte
}

\author{
Key Words \\ Walkability; Urban Spatial Quality; Small Town
}

\section{RESUMO}

A caminhabilidade pode ser entendida como um aspecto qualitativo do lugar que permite ao pedestre acessar os diferentes pontos da cidade. Desse modo, avaliar a qualidade dos percursos diários dos citadinos se mostra imprescindível para compreender o quão convidativo é o deslocamento pedonal. O objetivo deste trabalho é apresentar os resultados dos níveis de caminhabilidade de trajetos cotidianos realizados na cidade de Goiás (GO), localizada no centro-oeste brasileiro. A revisão bibliográfica fundamentou a sistematização dos parâmetros de qualidade do espaço. Em um primeiro momento, certificou-se o enquadramento dos percursos a uma distância ideal para os deslocamentos a pé. Em seguida, os critérios de análise da qualidade espacial foram definidos, constituídos de cenários com possibilidade de ocorrência no meio urbano, valorados a uma escala de zero a cinco. Os percursos analisados foram divididos em trechos aos quais foram verificados os critérios analíticos. Os resultados mostram que a cidade possui condições desfavoráveis à caminhabilidade, com equipamentos de uso cotidiano localizados a distâncias pouco convidativas ao deslocamento a pé e infraestrutura pedonal subdimensionada, apresentando ainda pouca proteção às intempéries, oferta insuficiente de mobiliários de apoio e obstáculos nas calçadas, desestimulando o deslocamento a pé nessa cidade de pequeno porte.

\section{ABSTRACT}

Walkability can be understood as a qualitative aspect of space, which allows pedestrians to access different points of the city. Thus, evaluating the quality of the city's daily journeys is essential for understanding how inviting displacement on foot is. The aim of this work is to present the results of walkability levels in daily paths held in Goiás city, located in Brazilian center-west region. The bibliographical review gave us basis for the systematization of space quality parameters. First, we verified the framing of those chosen trails into an ideal distance for displacement on foot. Then, we defined the analytical criteria for spatial quality, which were constituted by sceneries with possibility of occurrence into urban space, rated on a scale of zero to five. The analyzed trails were divided in parts, on which were verified the analytical criteria. The results show us that the city has unfavorable conditions for walkability, with daily use equipments located at distances that uninvite walk displacements. Also, the pedestrian infrastructure is undersized, offers little protection for weather conditions, insufficient urban furniture of support and obstacles on the sidewalks. This context discourages displacement on foot in this small town. 


\section{INTRODUÇÃO}

Caminhar é um meio de transporte, e tem a potencialidade de dar início ou criar oportunidade para outras atividades, fortalecendo a interação social. Muitos fatores influenciam no caminhar, e o projeto do espaço urbano pode ser determinante para promover uma boa caminhabilidade. Quando se fala de caminhabilidade, pode-se remeter a diversos conceitos, com variados critérios de avaliação, mas aqui ela é tratada, conforme apontado por Ghidini (2011, p.22), como "uma qualidade do lugar, o caminho que permite ao pedestre uma boa acessibilidade às diferentes partes da cidade", sobretudo, em percursos que ele faz no seu dia a dia. É importante pensar os espaços urbanos do ponto de vista de seus usuários cotidianos; são os citadinos que levam seus filhos à escola, vão ao banco ou aos órgãos públicos resolverem questões pessoais, vão em busca de atendimento médico. São eles que saem para almoçar, beber em algum bar local, ou levar a família para um sorvete na praça. E como é a qualidade desses percursos?

Pensar no ganho que se tem com espaços caminháveis no contexto urbano, necessariamente leva à reflexão de se trabalhar orientado ao desenvolvimento sustentável, que quer dizer, entre outras coisas, a redução de transportes motorizados em geral, com direta influência nos níveis de emissão de gases poluentes e nocivos; ganhos na área da saúde, reduzindo índices de obesidade ou melhorando o condicionamento cardiorrespiratório dos indivíduos; e a provisão de uma maior capacidade de atração de pedestres, aumentando o quantitativo e diversificando a uma gama mais ampla o perfil dos usuários dos espaços urbanos. Esse aumento de pedestres implica em uma maior interação entre as pessoas, aumenta a sensação de segurança entre elas, além da ativação econômica que gera, uma vez que mais pessoas circulando traduzem-se em mais pessoas tendo experiências de troca, compra e venda.

Esse cenário, no contexto de uma cidade de pequeno porte intensifica-se e se torna ainda mais propício, uma vez que por serem as distâncias reduzidas, além de todos os aspectos apontados, perde-se o sentido da utilização do automóvel. Nesse contexto, este trabalho analisou a cidade de Goiás - município com área aproximada de três mil quilômetros quadrados e população com pouco mais de vinte e quatro mil habitantes, segundo estimativa do IBGE para 2016, em relação ao censo de 2010 (PORTAL DO IBGE, 2016). Goiás-GO foi primeira capital do estado de mesmo nome, localizada no centro-oeste brasileiro, tendo surgido como resultado da exploração do ouro no interior do país empreendida pelos bandeirantes que colonizaram a região nos séculos XVIII e XIX.

Goiás foi sede administrativa da Capitania e do Estado, de 1744 até 1937, quando ocorreu a transferência oficial da capital estadual para Goiânia. Seu conjunto urbanístico e arquitetônico manteve as características da trama urbana original, dos espaços públicos e privados, da escala e da volumetria das suas edificações. Teve alguns de seus monumentos e edifícios isoladamente classificados pelo IPHAN (Instituto do Patrimônio Histórico e Artístico Nacional) em 1950, e o mesmo órgão em 1978 tombou sua paisagem cultural. Em dezembro de 2001, Goiás foi reconhecida como Patrimônio Cultural Mundial, pela UNESCO (Organização das Nações Unidas para a Educação, a Ciência e a Cultura). Considerada, portanto, uma cidade de pequeno porte, a vida diária do município passa por seu centro histórico, local que remonta às primeiras construções, e onde se concentram bancos, instituições públicas de diversos segmentos, cartório e grande oferta de serviços, comércio e equipamentos de lazer.

Apesar de seu porte, a mobilidade urbana em Goiás acontece em veículos particulares: há disponível apenas uma linha municipal de ônibus, gratuita, que percorre a cidade em horários incertos e atualmente somente um veículo oferece o serviço à população. Tal linha atravessa diferentes bairros da cidade e circula nas periferias da área central, sem, contudo, contemplá-la. Nesse contexto, é comum que os habitantes se desloquem em seus próprios carros e motocicletas, ou contratem os serviços de táxis e mototáxis. Há uma parcela da população que se desloca a pé ou, em menor quantidade, em bicicletas. Contudo, o relevo extremamente acidentado e as temperaturas elevadas na maior parte do tempo, são adversidades naturais ao deslocamento não-motorizado.

Speck (2012) ao analisar o deslocamento de pedestres em cidades como Roma afirma que, a despeito de um relevo extremamente acidentado, de ruas estreitas, da ausência de calçadas em metade delas, da inexistência de faixa de pedestres em cruzamentos, de uma pavimentação desigual e esburacada, e da ausência de rampas para deficientes ou outros aspectos que se referem à acessibilidade, os pedestres circulam pela cidade ou por seus bairros mais tradicionais, favorecidos pela trama urbana. Se a trama urbana, definida por Speck $(2012$, p.10) como o "conjunto diário de ruas, quarteirões e edificações que amarram os monumentos juntos" influencia na caminhabilidade, ela não pode ser tratada como o único aspecto a ser aferido, para se considerar tal cidade ou uma área específica caminhável ou não. A descrição de entraves ao 
deslocamento no meio urbano de Roma em muito se assemelha aos de Goiás, mas quais aspectos seriam necessários para garantir um ambiente caminhável favorável ao pedestre? Neste espectro, o objetivo deste trabalho é investigar os principais percursos feitos por um morador de Goiás em sua vida diária, por duas perspectivas: através das distâncias percorridas e sua qualidade, cujos critérios são abordados a seguir.

\section{REFERENCIAL TEÓRICO}

O intuito de mensurar os níveis de caminhabilidade de um determinado espaço urbano se iniciou com o trabaIho de Bradshaw, no início dos anos 1990 (GHIDINI, 2011). No Brasil, algumas experiências envolvendo a mensuração da caminhabilidade também foram desenvolvidas. Inspirados pelas discussões da humanização do espaço urbano promovidas por Jan Gehl (2013), o trabalho de Barros et al. (2015), apresenta um vasto detalhamento de categorias de avaliação da qualidade urbana e seus respectivos indicadores. O mesmo ocorre com a pesquisa empreendida por Gonçalves et al. (2015), que aplicando a metodologia do Núcleo de Estudos em Mobilidade Urbana - NMob da Universidade Federal da Bahia e a do Núcleo de Arquitetura e Urbanismo da Universidade Federal de Sergipe, sistematiza critérios de aferição da caminhabilidade. O estudo de Nanya \& Sanches (2015, p. 1705) é de fundamental importância por se propor a desenvolver um instrumental de avaliação da caminhabilidade a partir da geração de índices que poderiam ser aplicados em qualquer contexto urbano.

Em suma, os trabalhos que avaliam os índices de caminhabilidade nas cidades devem, em primeira instância, buscar parâmetros de definição dessa qualidade de percurso. Em geral, há algumas categorias de análise da qualidade dos trechos de calçadas que são recorrentes nesses estudos: largura, condições de pavimentação, obstáculos, nivelamento de pisos, proteção de intempéries, mobiliário urbano, iluminação pública, usos lindeiros e diversidade urbana, segurança, densidade de pessoas e fluxos, integração com transporte público, paisagem, gabarito de edificações, desenho urbano, arborização, poluição, acessibilidade, sinalização, limpeza e topografia. Outro ponto que esses trabalhos possuem em comum são os critérios para avaliação dessas categorias, que se constituem de cenários que podem ser encontrados em campo, seguidos de uma pontuação que lhes é atribuída.

A exposição dos critérios e meios de avaliação da qualidade do espaço urbano abordada nesses diferentes trabalhos mostra o que é comentado por Nanya \&
Sanches (2015, p. 1703): "o conjunto de atributos utilizados por cada pesquisador para definir a caminhabilidade é muito variável e, em geral, bastante grande". Nesse sentido, o exercício de designação de parâmetros para a aferição da caminhabilidade se inicia com o entendimento de quais são os itens pertinentes à análise nas cidades em questão. Igualmente, as definições dos cenários e as escalas de gradações possíveis para cada item avaliado dependem das condicionantes sociais, culturais e geográficas do local. Desse modo, ainda que trabalhos como o de Nanya \& Sanches (2015) proponham parâmetros gerais para avaliação, que certamente podem ser aplicados, o exercício de aferição da caminhabilidade se torna exclusivo a cada novo contexto, com um elenco de categorias de análise e cenários que surgem como objeto de reflexão da cidade real.

\section{METODOLOGIA}

O processo analítico da caminhabilidade proposto neste trabalho parte de uma primeira categoria de análise pouco mencionada nos estudos consultados: a distância dos percursos. Para a avaliação da caminhabilidade na cidade de Goiás, foram elencados cinco percursos em seu centro histórico, que simulam trajetos cotidianos a partir de um ponto inicial - uma casa -, escolhida estrategicamente em uma área de predominância residencial. Tais trajetos compreendem o acesso de menor distância aos exemplares mais próximos do referido ponto que possuem a seguinte natureza: uma escola, um espaço de lazer, um estabelecimento de saúde, um mercado e uma agência bancária conforme apontado na Figura 1. Dessa forma, o primeiro item analisado é se esses estabelecimentos, recorrentes no dia-a-dia do cidadão se encontram a uma distância convidativa ao deslocamento pedonal, favorecendo a caminhabilidade.

Conforme mencionado por Gehl (2013, p.121), "a distância aceitável de caminhada é um conceito relativamente fluido". A disposição a caminhar por trajetos maiores a pé depende da pré-disposição e limitações da pessoa em fazê-lo. Em um segundo plano, a topografia, a qualidade do percurso, da paisagem e as condições climáticas são alguns fatores que também podem relativizar a adoção de uma distância ideal para o deslocamento a pé. Porém, o que é argumentado por Gehl (2013, p.121) é que "boa parte das pessoas está disposta a percorrer cerca de 500 metros". Allen \& Farr (2013, p.126) também avaliam que o atendimento às necessidades diárias a pé em uma determinada área se torna muito mais conveniente e provável quando os destinos se desenvolvem de modo agrupado e 
a uma distância confortável para o acesso por caminhada. Para os autores, essa distância favorável é de 400 metros (ALLEN \& FARR, 2013, p.126). Na ausência de consenso sobre a distância ideal para a caminhada, tomando como ponto de partida o postulado por Gehl (2013) e Allen \& Farr (2013), foi considerado como um balizador da categoria analítica de distância, um valor intermediário aos dos autores. Desse modo, a distância desses percursos medida em base cartográfica por acesso remoto será considerada inadequada ao deslocamento pedonal quando superior à marca dos 450 metros.

A análise da caminhabilidade pelo viés da qualidade se inicia em sequência, a partir da seleção dos trechos (Figura 1), aos quais serão aferidos os critérios de análise. Considera-se como trecho cada porção de calçada localizada entre travessias. As categorias analíticas - num total de onze - compreendem (i) largura da calçada, (ii) condições de pavimentação, (iii) obstáculos, (iv) proteção de intempéries, (v) mobiliário urbano de apoio, (vi) iluminação pública, (vii) usos lindeiros ao trajeto, (viii) segurança e orientação, (xix) qualidade da paisagem, (xx) vegetação, e, (xi) topografia. Cada categoria apresenta seis cenários, elencados considerando as condicionantes locais de Goiás, e previamente valoradas entre 0 (zero) trecho percorrido, é feito um levantamento dos cenários encontrados, dentro de cada categoria, e em seguida feita uma média aritmética resultando em uma nota parcial por categoria.

Figura 1 - Percursos analisados na cidade de Goiás divididos em trechos Fonte: elaborado pelos autores sobre base Google.

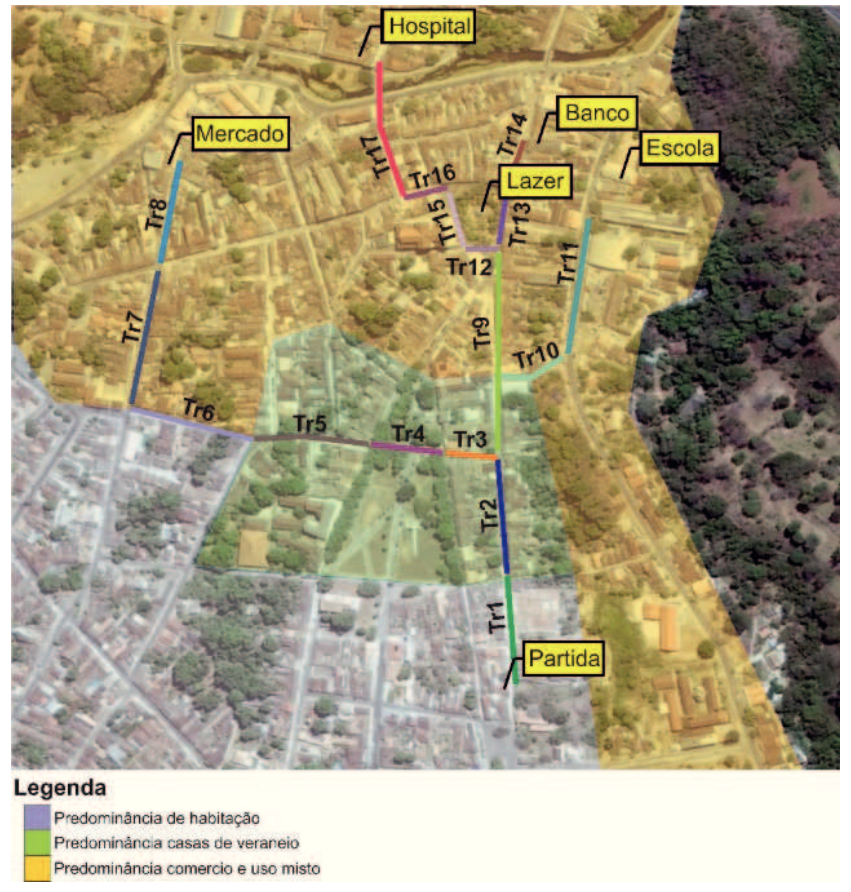

Tabela 1 - Critérios de análise da qualidade.

\begin{tabular}{|c|c|c|}
\hline Categoria & Cenário & Valor \\
\hline Largura da calçada & $\begin{array}{l}\text { Calçada ausente } \\
\text { Calçada com menos de } 0,75 \mathrm{~m} \\
\text { Calçada entre } 0,75 \mathrm{~m} \text { e } 1,0 \mathrm{~m} \\
\text { Calçada entre } 1,0 \mathrm{~m} \text { e } 1,5 \mathrm{~m} \\
\text { Calçada entre } 1,5 \mathrm{~m} \text { e } 2,5 \mathrm{~m} \\
\text { Calçada com mais de } 2,5 \mathrm{~m}\end{array}$ & $\begin{array}{l}0 \\
1 \\
2 \\
3 \\
4 \\
5\end{array}$ \\
\hline $\begin{array}{l}\text { Condições de } \\
\text { pavimentação }\end{array}$ & $\begin{array}{l}\text { Calçada sem pavimentação } \\
\text { Calçada com pavimentação parcial } \\
\text { Calçada com depressões } \\
\text { Calçada com pavimentação em bom estado } \\
\text { Calçada com pavimentação antiderrapante } \\
\text { Calçada com pavimentação antiderrapante e com piso tátil de alerta e direcional }\end{array}$ & $\begin{array}{l}0 \\
1 \\
2 \\
3 \\
4 \\
5\end{array}$ \\
\hline Obstáculos & $\begin{array}{l}\text { Obstáculo intransponível } \\
\text { Obstáculo contornável reduzindo a faixa de circulação a menos que } 0,6 \mathrm{~m} \\
\text { Calçada com degrau maior que } 0,18 \mathrm{~m} \text { ou com rampa } \\
\text { Calçada com degraus menores que } 0,18 \mathrm{~m} \\
\text { Obstáculo contornável reduzindo a faixa de circulação a menos que } 1,20 \mathrm{~m} \\
\text { Calçada sem obstáculos }\end{array}$ & $\begin{array}{l}0 \\
1 \\
2 \\
3 \\
4 \\
5\end{array}$ \\
\hline
\end{tabular}




\begin{tabular}{|c|c|c|}
\hline Categoria & Cenário & Valor \\
\hline $\begin{array}{l}\text { Proteção de } \\
\text { intempéries }\end{array}$ & $\begin{array}{l}\text { Proteção inexistente } \\
\text { Cobertura pontual } \\
\text { Cobertura em } 25 \% \text { da calçada } \\
\text { Cobertura em } 50 \% \text { da calçada } \\
\text { Cobertura em } 75 \% \text { da calçada } \\
\text { Cobertura total na calçada }\end{array}$ & $\begin{array}{l}0 \\
1 \\
2 \\
3 \\
4 \\
5\end{array}$ \\
\hline $\begin{array}{l}\text { Mobiliário urbano } \\
\text { de apoio }\end{array}$ & $\begin{array}{l}\text { Inexistência de mobiliário urbano de apoio } \\
\text { Calçada com } 1 \text { item de mobiliário urbano, mas não de permanência danificado } \\
\text { Calçada com } 1 \text { item de mobiliário urbano, mas não de permanência } \\
\text { Calçada com } 1 \text { item de mobiliário urbano de permanência danificado } \\
\text { Calçada com } 1 \text { item de mobiliário urbano de permanência em bom estado } \\
\text { Calçada com mais de } 1 \text { item de mobiliário urbano de permanência em bom estado }\end{array}$ & $\begin{array}{l}0 \\
1 \\
2 \\
3 \\
4 \\
5\end{array}$ \\
\hline Iluminação pública & $\begin{array}{l}\text { Inexistência de iluminação pública } \\
\text { Iluminação pública de automóveis com pontos de obscurecência } \\
\text { lluminação pública de automóveis em bom estado de conservação } \\
\text { lluminação pedonal com pontos de obscurecência } \\
\text { Iluminação pedonal em intervalos regulares e com bom estado de conservação } \\
\text { Iluminação de automóveis e pedonal com bom estado de conservação }\end{array}$ & $\begin{array}{l}0 \\
1 \\
2 \\
3 \\
4 \\
5\end{array}$ \\
\hline $\begin{array}{l}\text { Usos lindeiros ao } \\
\text { trajeto }\end{array}$ & $\begin{array}{l}\text { Muros e terrenos baldios } \\
\text { Uso exclusivamente residencial } \\
\text { Uso exclusivamente comercial e institucional } \\
\text { Uso misto com poucas com pouca movimentação nas calçadas } \\
\text { Uso misto com movimentação moderada nas calçadas } \\
\text { Uso misto com grande movimentação nas calçadas }\end{array}$ & $\begin{array}{l}0 \\
1 \\
2 \\
3 \\
4 \\
5\end{array}$ \\
\hline $\begin{array}{l}\text { Segurança e } \\
\text { orientação }\end{array}$ & $\begin{array}{l}\text { Ausência de faixas de pedestre e sinalização } \\
\text { Faixas de pedestre e sinalização em mau estado de conservação } \\
\text { Faixas de pedestre com obstrução de visão } \\
\text { Faixas de pedestre em bom estado de conservação e sem rampas } \\
\text { Faixas de pedestre em bom estado de conservação e com rampas } \\
\text { Faixas de pedestres elevadas e com boa sinalização }\end{array}$ & $\begin{array}{l}0 \\
1 \\
2 \\
3 \\
4 \\
5\end{array}$ \\
\hline $\begin{array}{l}\text { Qualidade da } \\
\text { paisagem }\end{array}$ & $\begin{array}{l}\text { Construções sem diálogo com o espaço público } \\
\text { Construções em mau estado de conservação e/ou abandonadas } \\
\text { Construções parcialmente em diálogo com o espaço público } \\
\text { Construções em bom estado de conservação e com aberturas fechadas } \\
\text { Construções em bom estado de conservação e com aberturas abertas } \\
\text { Construções com grandes aberturas para o espaço público ou com áreas ajardinadas }\end{array}$ & $\begin{array}{l}0 \\
1 \\
2 \\
3 \\
4 \\
5\end{array}$ \\
\hline Vegetação & $\begin{array}{l}\text { Sem vegetação } \\
\text { Vegetação insuficiente } \\
\text { Vegetação de forração pontual } \\
\text { Vegetação arbustiva pontual } \\
\text { Vegetação arbórea em parte do trecho } \\
\text { Vegetação arbórea ao longo do trecho }\end{array}$ & $\begin{array}{l}0 \\
1 \\
2 \\
3 \\
4 \\
5\end{array}$ \\
\hline Topografia & $\begin{array}{l}\text { Inclinação maior que } 20 \% \\
\text { Inclinação } 10 \% \text { e } 20 \% \\
\text { Inclinação entre } 8 \% \text { e } 10 \% \\
\text { Inclinação entre } 5 \% \text { e } 8 \% \\
\text { Inclinação entre } 1 \% \text { e } 5 \% \\
\text { Plano }\end{array}$ & $\begin{array}{l}0 \\
1 \\
2 \\
3 \\
4 \\
5\end{array}$ \\
\hline
\end{tabular}


Para obter a nota de cada trecho, é feita uma média aritmética com as notas parciais de cada categoria, totalizando a nota final de caminhabilidade por trecho. Ao final, é feita nova média aritmética das notas dos trechos que compõem cada percurso, indicando qual deles é o mais e qual é o menos caminhável, a partir de características qualitativas do espaço urbano.

\section{RESULTADOS}

O resultado da análise das distâncias dos percursos que simulam trajetos cotidianos a partir de um ponto inicial está sistematizado e ilustrado na Figura 2. Trançando um raio de 400 metros (ALLEN \& FARR, 2013), 450 metros (Autores) e 500 metros (GEHL, 2013), tendo o ponto de partida do percurso como centro da circunferência, ficou evidente que apenas o acesso ao lazer (460 m) está dentro das distâncias ao deslocamento pedonal estabelecidas por Gehl (2013) e os demais acessos ficando fora das distâncias que favorecem a caminhabilidade utilizadas neste trabalho. O resultado da primeira parte da pesquisa demonstra de forma simplificada que as distâncias percorridas para locais de uso cotidianos no centro histórico da cidade de Goiás tendem a uma menor força convidativa a caminhabilidade e a um possível convite a um desloca-

Figura 2 - Distâncias de caminhada.

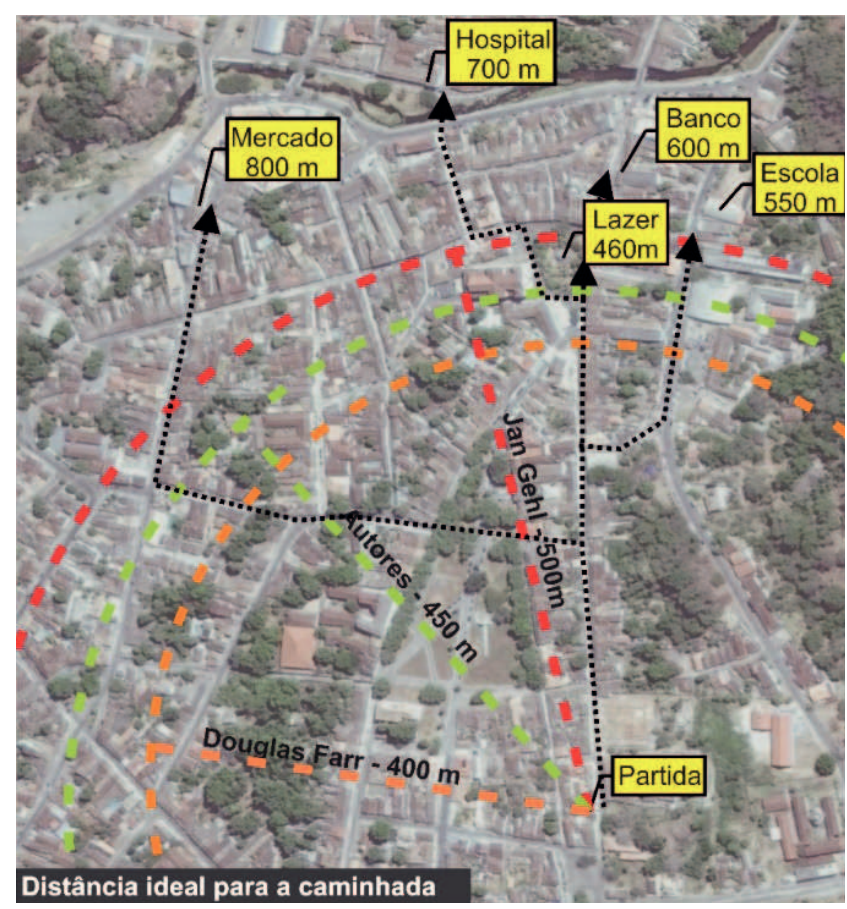

Fonte: Mapa elaborado pelos autores sobre base Google.

Procedeu-se, portanto, ao levantamento analítico de cada um dos dezessete trechos que compõem os trajetos elencados, segundo as onze categorias e seus cenários, obtendo as notas parciais por categoria e as notas finais de cada trecho, conforme descrito no Quadro 2. De posse dessas notas, fez-se necessária a composição das notas de cada um dos percursos. O percurso 'residência-mercado' - composto pelos trechos 1, 2, 3, 4, 5, 6, 7 e 8 - teve nota final 1,51; o 'residência-hospital' - pelos trechos 1 , 2, 9, 12, 15, 16 e 17 - teve nota 1,79; o 'residência-lazer' - pelos trechos 1, 2, 9 e 12 - nota 1,65; o 'residência-banco' - por 1, 2, 9, 13 e 14 - nota 1,78; e, por fim, o percurso 'residência-escola' - que se compôs pelos trechos 1, 2, 9, 10 e 11 - teve nota 1,26, conforme mostra o Quadro 3. Uma ilustração dos principais entraves ao deslocamento encontrados nos trechos aparece nas imagens que compõem a Figura 3, abaixo.

Figura 3: Entraves ao deslocamento em diferentes trechos.
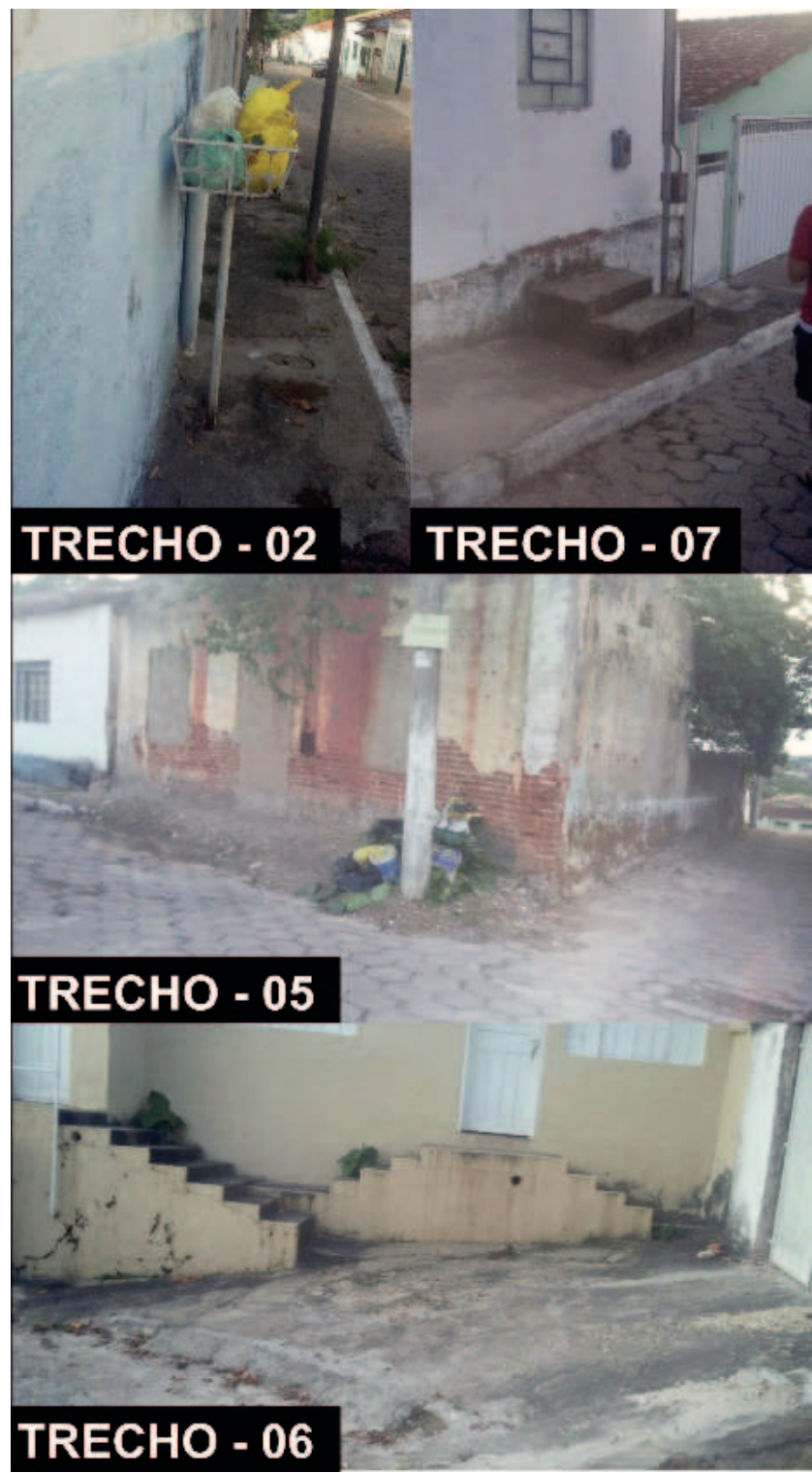

Fonte: Autores 
Para cada categoria, como já explicitado, os cenários foram valorados de 0 a 5 , correspondendo o 0 à pior condição de caminhar, e o 5, à melhor condição do deslocamento pedonal. Ao consolidar as notas finais, é possível confirmar a percepção inicial dos pesquisadores enquanto pedestres de que a caminhabilidade no centro histórico da cidade de Goiás é de péssima qualidade. Nenhum dos cinco percursos analisados obteve nota acima de 2 , recebendo, o melhor deles, nota 1,79.

Os resultados apontam que há um padrão nas ruas de Goiás, mas os cenários que, sim, são recorrentes, infelizmente apontam para a ausência de calçada ou a mesma com largura inferior a 0,75m, com pavimentação com depressões e extremamente irregular, apresentando obstáculos que - embora contornáveis - reduzem ainda mais a já estreita faixa de circulação, lançando os pedestres na via carroçável e os expondo ao risco de um atropelamento ou acidente qualquer. Observa-se também a pouca ocorrência de proteção contra intempéries, aparecendo pontualmente apenas em alguns estabelecimentos comerciais, mas sem continuidade ou integração entre si, e alguns em mau estado de conservação, assim como não se vê mobiliário urbano de apoio. A iluminação pública é a categoria que melhor se apresenta, com certa regularidade em todos os percursos, ficando apenas alguns trechos mal iluminados, enquanto no tocante à segurança e orientação, é quase geral a inexistência de faixas de pedestres e sinalização. Quando há, aparecem bastante desgastadas.

Tabela 2 - Levantamento de análise da qualidade.

\begin{tabular}{|l|c|c|c|c|c|c|c|c|c|c|c|c|c|c|c|c|c|}
\hline Categoria & $\operatorname{Tr} \mathbf{0 1}$ & $\operatorname{Tr} \mathbf{0 2}$ & $\operatorname{Tr} \mathbf{0 3}$ & $\operatorname{Tr} \mathbf{0 4}$ & $\operatorname{Tr} \mathbf{0 5}$ & $\operatorname{Tr} \mathbf{0 6}$ & $\operatorname{Tr} \mathbf{0 7}$ & $\operatorname{Tr} \mathbf{0 8}$ & $\operatorname{Tr} \mathbf{0 9}$ & $\operatorname{Tr} \mathbf{1 0}$ & $\operatorname{Tr} \mathbf{1 1}$ & $\operatorname{Tr} \mathbf{1 2}$ & $\operatorname{Tr} \mathbf{1 3}$ & $\operatorname{Tr} \mathbf{1 4}$ & $\operatorname{Tr} \mathbf{1 5}$ & $\operatorname{Tr} \mathbf{1 6}$ & $\operatorname{Tr} \mathbf{1 7}$ \\
\hline $\begin{array}{l}\text { Largura da } \\
\text { calçada }\end{array}$ & 1 & 2 & 0,5 & 0 & 1,5 & 0,5 & 3 & 3 & 1 & 0,5 & 1,5 & 0,5 & 0,5 & 3 & 0,5 & 0,5 & 2 \\
\hline $\begin{array}{l}\text { Condições de } \\
\text { pavimentação }\end{array}$ & 1,67 & 2,5 & 1,5 & 0 & 2 & 2 & 2,5 & 2,5 & 1,67 & 0,5 & 2 & 0 & 0 & 2,5 & 0 & 0,5 & 2,5 \\
\hline Obstáculos & 1 & 2,5 & 0,5 & 0 & 0,5 & 0 & 1,33 & 2,67 & 1 & 0,5 & 1 & 1,5 & 1,5 & 3 & 1,5 & 0,5 & 1,5 \\
\hline $\begin{array}{l}\text { Proteção de } \\
\text { intempéries }\end{array}$ & 0 & 0 & 0 & 2 & 0 & 0 & 1 & 1 & 0 & 0 & 0 & 1,5 & 1,5 & 0 & 1,5 & 0 & 0 \\
\hline $\begin{array}{l}\text { Mobiliário } \\
\text { urbano de } \\
\text { apoio }\end{array}$ & 0 & 0 & 0 & 0 & 0 & 0 & 0 & 0 & 0 & 0 & 0 & 5 & 5 & 0 & 5 & 0 & 0 \\
\hline $\begin{array}{l}\text { Iluminação } \\
\text { pública }\end{array}$ & 4 & 4 & 4 & 4 & 2 & 2 & 2 & 2 & 3 & 1 & 2 & 4 & 4 & 4 & 4 & 1 & 2 \\
\hline $\begin{array}{l}\text { Usos lindeiros } \\
\text { ao trajeto }\end{array}$ & 2,33 & 2 & 1,5 & 0 & 1,5 & 1,5 & 5 & 2 & 2 & 1,5 & 2 & 5 & 5 & 5 & 5 & 1,5 & 2 \\
\hline $\begin{array}{l}\text { Segurança e } \\
\text { orientação }\end{array}$ & 0 & 0 & 0 & 0 & 1 & 0 & 1 & 1 & 0 & 0 & 1 & 0 & 0 & 0 & 0 & 0 & 0 \\
\hline $\begin{array}{l}\text { Qualidade da } \\
\text { paisagem }\end{array}$ & 4 & 1,67 & 2 & 5 & 3 & 2 & 2,5 & 2,5 & 1,67 & 1,67 & 1,67 & 4 & 4 & 4 & 4 & 1,67 & 4 \\
\hline Vegetação & 0 & 0 & 0 & 3,5 & 0 & 0 & 0 & 0 & 0 & 0 & 0,5 & 3 & 3 & 0 & 3 & 0 & 0 \\
\hline Topografia & 1 & 2 & 4 & 4 & 3 & 1 & 5 & 5 & 3 & 3 & 4 & 3 & 3 & 4 & 3 & 3 & 5 \\
\hline $\begin{array}{l}\text { Média Final } \\
\text { do Trecho }\end{array}$ & 1,36 & 1,52 & 1,27 & 1,68 & 1,3 & 0,82 & 2,12 & 1,97 & 1,21 & 0,79 & 1,42 & 2,5 & 2,5 & 2,32 & 2,5 & 0,79 & 1,73 \\
\hline
\end{tabular}

Tabela 3 - Notas finais de caminhabilidade por percurso. Fonte: elaborado pelos autores.

\begin{tabular}{|l|l|l|}
\hline Percurso & Trechos abrangidos & Nota final \\
\hline Mercado & $1,2,3,4,5,6,7$ e 8 & 1,51 \\
\hline Hospital & $1,2,9,12,15,16$ e 17 & 1,79 \\
\hline Lazer & $1,2,9$ e 12 & 1,65 \\
\hline Banco & $1,2,9,13$ e 14 & 1,78 \\
\hline Escola & $1,2,9,10$ e 11 & 1,26 \\
\hline
\end{tabular}


No que diz respeito aos usos lindeiros ao trajeto, estes apresentam uso predominantemente residencial ou misto, com pouca ou moderada movimentação nas calçadas, e não raramente observa-se a ocorrência de longos muros e edificações sem diálogo com o espaço público. A qualidade da paisagem se apresenta comprometida em muitos pontos por edificações em mau estado de conservação, cuja volumetria e implantação se mostram em diálogo com o espaço público, seja na proporcionalidade que apresentam com as dimensões da via, seja na linguagem colonial, mas que em muitos casos encontram-se abandonadas. Os resultados confirmam, ainda, o que se percebe naturalmente ao caminhar não só nestes percursos, mas por toda a cidade: a incidência de uma topografia irregular, onde ruas planas se alternam com aclives de inclinação diversa, sendo em alguns casos de difícil transposição.

A exceção a esse padrão acontece nas praças do Chafariz e do Coreto (trechos TR4, TR12, TR13 e TR15), cortadas por alguns desses percursos, que apresentam meIhores condições de caminhabilidade, sem serem ainda, ideais, mas com a presença de mobiliário urbano de apoio e abundância de vegetação diversa. A iluminação pública é adequada, as construções predominam em uso misto e há movimentação de moderada a grande nas calçadas estreitas e sem proteção contra intempéries. Todos esses fatores fornecem pistas que justificam a inibição do deslocamento a pé e a baixa densidade de pessoas nas ruas do centro histórico, especialmente nas horas mais quentes do dia, onde a falta de proteção das calçadas e sua constituição em grande parte de pedra, acentuam a sensação desconfortante do calor.

\section{CONCLUSÕES}

Goiás é uma cidade de pequeno porte que poderia apresentar variados fatores estimulantes ao deslocamento a pé em seu centro histórico. A beleza de sua paisagem colonial, a estreita relação de proporcionalidade e a escala que suas edificações guardam com suas vielas rústicas são, por si só, um convite ao deslocamento a pé, apreciando cada detalhe de seu ambiente construído. Contudo, a beleza de sua paisagem cultural, conservada nos critérios de preservação do IPHAN, não é suficiente para a garantia de um índice elevado de pedestres no espaço público. A insegurança em trechos repletos de obstáculos, a falta de orientação visual, a tendência a uma certa monotonia da paisagem - muitas vezes repleta de exemplares ora abandonados, ora fechados -, retiram muitos dos atributos de vitalidade urbana essenciais no conceito de caminhabilidade. O contexto de Goiás mostra que, mais além, há um fator característico dessa cidade do centro-oeste brasileiro, que não pode ser negligenciado: as altas temperaturas e as condicionantes geográficas que impedem a incidência de ventos. O fator humano deve estar em primeiro lugar no projeto de um ambiente urbano que se proponha mais caminhável, menos motorizado e mais vital do ponto de vista social. O desconforto e cansaço físico gerado pelas altas temperaturas parecem ser o ponto de maior vulnerabilidade nos quesitos de caminhabilidade em Goiás, traduzidos por um cenário com pouca proteção às intempéries e com insuficiência de mobiliário de apoio. Tal fator induz a pensar se nos estudos de caminhabilidade há pesos correspondentes aos variados critérios que devam ser mensurados, assim como os impactos que esse meio físico deficiente imprimem ao organismo humano. Tais questões se mostram pertinentes para o aprimoramento de estudos futuros e para o embasamento de diretrizes projetuais que favoreçam o florescer de uma cidade mais humana e mais caminhável.

\section{REFERÊNCIAS}

ALLEN, E. \& FARR, D. Um bairro completo. FARR, D. (org.). Urbanismo Sustentável: desenho urbano com a natureza. Porto Alegre: Bookman, 2013.

BARROS, A. P. B. G.; MARTÍNEZ, L. M. G. \& VIEGAS, J. M.. A caminhabilidade sob a ótica das pessoas: o que promove e o que inibe o deslocamento a pé? In Ur. Barcelona: 2015; n 8.

GEHL, J. Cidades Para Pessoas. 2 ed. São Paulo: Perspectiva, 2013

GHIDINI, R. A caminhabilidade: medida urbana sustentável. In Revista dos Transportes Públicos - ANTP. São Paulo: 2011; v.33.

GONÇALVES, P.H.; MOURA, D. D. S.; COSTA RODRIGUES, L. T. \& GOMES, L. G. Avaliação da caminhabilidade nas ruas da cidade. In Revista Mirante. Anápolis (GO): 2015; v.8.

NANYA, L.M. \& SANCHES, S.P. Proposta de instrumento para auditoria e avaliação da caminhabilidade. In Congresso Nacional de Pesquisa em Transporte da ANPET. Ouro Preto, 2015. 
PORTAL IBGE. População estimada 2016. Disponível em <http://cidades.ibge.gov.br/xtras/perfil.php?lang=\&codmun $=520890 \&$ search $=$ goias $\mid$ goias $>$, acesso em 04 de novembro de 2016.

PORTAL IPHAN. Histórico da Cidade de Goiás (GO). Disponível em <http://portal.iphan.gov.br/pagina/detaIhes/362/>, acesso em 04 de novembro de 2016.

SPECK, J. Walkable city: how downtown can save America, one step at a time. Nova lorque: Farrar, Straus and Giroux, 2012. 